\title{
The G-protein-coupled long-chain fatty acid receptor GPR40 and glucose metabolism
}

\author{
Tsutomu Tomita ${ }^{1}{ }^{*}$, Kiminori Hosoda ${ }^{1}$, Junji Fujikura ${ }^{1}$, Nobuya Inagaki ${ }^{1}$ and Kazuwa Nakao \\ 1 Department of Diabetes, Endocrinology and Nutrition, Kyoto University Graduate School of Medicine, Kyoto, Japan \\ ${ }^{2}$ Medical Innovation Center, Kyoto University Graduate School of Medicine, Kyoto, Japan
}

\section{Edited by:}

Ikuo Kimura, Tokyo University of Agriculture and Technology, Japan

Reviewed by:

Carol Huang, University of Calgary, Canada

Kay Waud, Jones Institute for

Reproductive Medicine, USA

${ }^{*}$ Correspondence:

Tsutomu Tomita, Department of

Diabetes, Endocrinology and

Nutrition, Kyoto University Graduate

School of Medicine, 54 Shogoin

Kawaharacho, Sakyo, Kyoto 606-8507,

Japan

e-mail: tt@kuhp.kyoto-u.ac.jp
Free fatty acids (FFAs) play a pivotal role in metabolic control and cell signaling processes in various tissues. In particular, FFAs are known to augment glucose-stimulated insulin secretion by pancreatic beta cells, where fatty acid-derived metabolites, such as long-chain fatty acyl-CoAs, are believed to act as crucial effectors. Recently, G-protein-coupled receptor 40 (GPR40), a receptor for long-chain fatty acids, was reported to be highly expressed in pancreatic beta cells and involved in the regulation of insulin secretion. Hence, GPR40 is considered to be a potential therapeutic target for the treatment of diabetes. In this review, we summarize the identification and gene expression patterns of GPR40 and its role in glucose metabolism. We also discuss the potential application of GPR40 as a therapeutic target.

Keywords: GPR40, FFAR1, LCFA, insulin secretion, pancreatic beta cells

\section{INTRODUCTION}

Free fatty acids (FFAs) are essential nutrients that also act as signaling molecules in various tissues. Long-chain fatty acids (LCFAs) play a role in the augmentation of glucose-stimulated insulin secretion (GSIS) (1). GSIS was observed to be considerably decreased by FFA depletion following in vivo administration of nicotinic acid to rats (2) and humans (3). Thus, FFA-mediated augmentation is considered to be physiologically significant. However, the underlying mechanisms of FFA-mediated augmentation of GSIS have not been fully elucidated. Several investigators have recently demonstrated that FFAs act as ligands for membranebound G-protein-coupled receptors (GPCRs) such as G-proteincoupled receptor 40 (GPR40), GPR41, GPR43, and GPR120. Among these, GPR40 is preferentially expressed by pancreatic beta cells in rodents and augments GSIS after acute exposure to LCFAs, highlighting the role of GPR40 as a potential key molecule in the regulation of insulin secretion.

\section{LCFA RECEPTOR GPR40}

GPR40 consists of 300 residues and was originally reported as an orphan GPCR (4). GPR40 was deorphaned by screening using a fluorometric imaging plate reader (FLIPR) system, which detects increases in $\mathrm{Ca}^{2+}$ concentrations in cultured cells with transiently expressed GPR40 cDNA $(5,6)$. GPR40 is reportedly activated by LCFAs (C12-22) and several eicosanoids in theoretically physiological concentration ranges. The profiles of putative GPR40 ligands are well conserved among mice, rats, and humans (5).

\section{GPR40 GENE EXPRESSION IN RODENTS}

Among rat tissues, GPR40 mRNA is almost exclusively expressed in the pancreas. In pancreatic islets, GPR40 mRNA levels were found to be approximately 17 -fold higher than the levels in the pancreas, suggesting selective GPR40 expression by pancreatic islets.
Considerable amounts of GPR40 mRNA were detected in the pancreatic beta cell lines MIN6, betaTC-3, HIT-T15, and Rin5F but not in the pancreatic alpha cell line alphaTC1. Furthermore, in situ hybridization with rat pancreatic islets suggested that GPR40 mRNA is preferentially expressed in pancreatic beta cells (5).

Reports using anti-GPR40 antibodies suggest that GPR40 protein is also probably preferentially expressed in pancreatic islets $(7,8)$.

\section{ROLES OF GPR4O IN REGULATION OF INSULIN SECRETION}

In MIN6 cells, insulin secretion was augmented by LCFAs in a dose-dependent manner, and the augmentation was observed only under hyperglycemic conditions (11-22 mM) (5), indicating the LCFA-mediated augmentation of insulin secretion is glucosedependent. Silencing of GPR40 gene expression using siRNA almost abolished the augmentation effects of LCFAs, indicating that GPR40 is involved in LCFA-mediated regulation of insulin secretion. GPR40 is a class A GPCR, highlighting the potential of GPR40 as a target for novel anti-diabetic oral drugs with low risk of hypoglycemia, considering that LCFA-mediated augmentation of insulin secretion is glucose-dependent.

\section{GPR40 GENE EXPRESSION IN HUMANS}

Although GPR40 is reportedly preferentially expressed by pancreatic beta cells in both rats and mice, little is known about GPR40 gene expression in humans. In this context, we assessed GPR40 mRNA expression in fresh human tissues obtained during surgery $(9,10)$. Analysis of 12 specimens of non-tumor pancreatic tissues revealed a considerable amount of GPR40 mRNA in each. In three pancreatic islet tissues specimens, GPR40 mRNA levels were approximately 20 -fold higher than those in pancreatic tissues, comparable to the levels of sulfonylurea receptor 1 , which is 
known to be highly expressed in pancreatic beta cells. High levels of GPR40 mRNA were detected in insulinoma (beta cell tumor) tissues in three cases; in contrast, GPR40 mRNA was undetectable in glucagonoma (alpha cell tumor) tissues $(10,11)$. In human pancreas, GPR40 mRNA level is positively and significantly correlated with the insulinogenic index, an index reflecting the function of pancreatic beta cells. These results indicate that GPR40 is highly expressed in human pancreatic beta cells and possibly involved in the positive regulation of insulin secretion (10).

\section{REGULATION OF GPR4O GENE EXPRESSION}

Though the mechanisms underlying the regulation of GPR40 gene expression is not fully understood, possible mechanisms include the PDX-1/IPF1 (12), which reportedly binds to the promoter region of the GPR40 gene (13). Moreover, nutrients and therapeutic drugs such as glucose (12), palmitate, and rosiglitazone (8) are reportedly involved in the regulation of GPR40 gene expressions.

\section{THERAPEUTIC IMPLICATIONS OF GPR40}

Although an initial report of systemic GPR40 knockout (KO) mice and beta cell-specific GPR40 transgenic (Tg) mice using the PDX1/IPF1 promoter suggested possible involvement of GPR40 in insulin resistance in the liver and beta cell failure (14), later reports using GPR40 KO mice found no link between GPR40 and beta cell dysfunction $(15,16)$. Studies using GPR40 KO mice suggest the implication of GPR40 in the regulation of insulin secretion, at least under some conditions including loading of intralipid (17), high-fat diet (15), hyperglycemic glucose clamp, and arginine (18). Furthermore, GPR40 Tg mice with the mouse INS2 promoter exhibited better glucose tolerance with enhanced GSIS (19), suggesting therapeutic implications of GPR40 rather than a gateway of beta cell toxicity.

Additionally, recent reports suggest that GPR40 is expressed in enteroendocrine cells and involved in the positive regulation of intestinal hormones including glucagon-like peptide-1 (GLP-1), glucose-dependent insulinotropic polypeptide (GIP), and cholecystokinin (20-22).

\section{GPR40 AG0NISTS AS ANTI-DIABETIC DRUGS}

Recently, TAK-875 (Fasiglifam), a novel GPR40 selective agonist (23), was reported as a potential oral anti-diabetic drug. The potency of TAK- 875 is approximately 400 -fold greater than that of the endogenous ligand oleic acid (24), and it does not activate GPR120 (23), another GPCR for LCFAs. TAK-875 augmented insulin secretion under high-glucose conditions in the rat pancreatic beta cell line INS1 833/14 (24) and human pancreatic islets (25) but did not affect glucagon secretion in humans (25), in accordance with the observations in humans by our group and others (9-11). TAK-875 significantly improved glycemic control with the augmentation of insulin secretion in diabetic rat models such as Wistar fatty rats (23) and Zucker diabetic fatty rats (24).

In phase 2, randomized, double-blind, placebo-controlled trial in patients with type 2 diabetes, HbAlc was decreased in a dosedependent manner in TAK-875 groups, and the HbA1c-lowering effect (50-200 mg, approximately - 1.1\% in 12 weeks) was comparable to that in glimepiride ( $4 \mathrm{mg}$ ) group, while the incidence of hypoglycemia in TAK-875 was similar to the placebo group

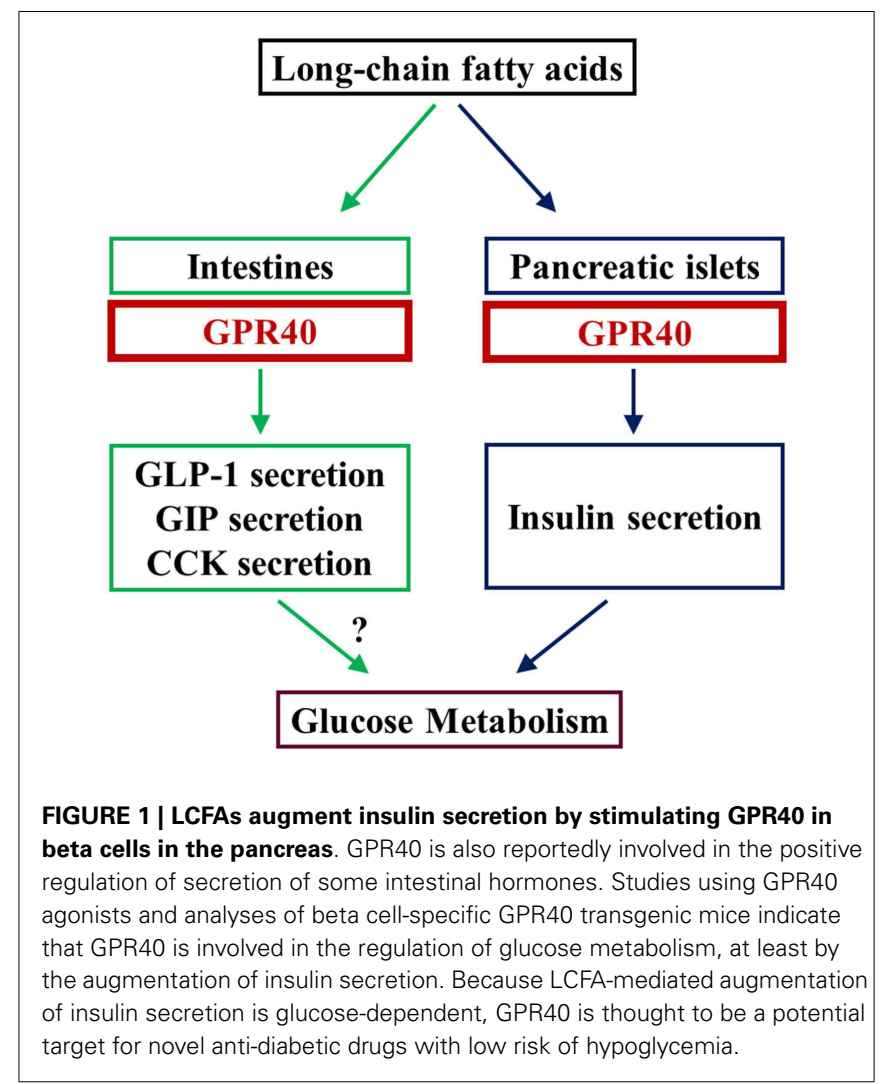

and markedly lower than the glimepiride group (26). In Japanese patients with type 2 diabetes, 12 -week treatment with TAK-875 also decreased $\mathrm{HbA} 1 \mathrm{c}$ levels in a dose-dependent manner, and the HbAlc-lowering effect (50-200 mg, approximately -1.3\%) was comparable to that in the glimepiride (1 mg) group (27).

Though TAK- 875 seemed to be a promising anti-diabetic drug, regrettably, its development was terminated in 2013 because of the risk of possible liver damage. Although the cause of the liver damage remains unclear, GPR40 is not expressed in the human liver $(6,10)$, suggesting that the toxicity may not be due to the GPR40 receptor itself but chemical characteristic of TAK- 875 or its dose used in the clinical trials. Still, several GPR40 agonists continue to be evaluated in both preclinical (Bristol-Myers Squibb, Merck, Amgen, Johnson \& Johnson, Astellas, Daiichi Sankyo, Piramal, and Connexios) and clinical (Japan Tobacco) trials, and the further development is expected in the study elucidating the significance of GPR40 in glucose and other metabolism.

\section{CONCLUSION}

Incretin mimetic-type drugs have been implicated in GPCRmediated regulation of insulin secretion in diabetes. GPR40 is a GPCR that is highly expressed in pancreatic beta cells and involved in insulin secretion in rodents and humans. Hence, GPR40 is a potential therapeutic target in diabetes, which can lead to the development of oral drugs with fewer hypoglycemic side effects. Furthermore, GPR40 is reportedly implicated in the regulation of incretin secretion from enteroendocrine cells. GPR40 may be important to unveil the link between FFA signaling and beta 
cell function as well as glucose metabolism (Figure 1). Hence, further studies are warranted to elucidate the physiological and pathophysiological implications of GPR40.

\section{REFERENCES}

1. Stein DT, Esser V, Stevenson BE, Lane KE, Whiteside JH, Daniels MB, et al. Essentiality of circulating fatty acids for glucose-stimulated insulin secretion in the fasted rat. J Clin Invest (1996) 97:2728-35. doi:10.1172/JCI118727

2. Dobbins RL, Chester MW, Stevenson BE, Daniels MB, Stein DT, McGarry JD. A fatty acid-dependent step is critically important for both glucose- and non-glucose-stimulated insulin secretion. J Clin Invest (1998) 101:2370-6. doi:10.1172/JCI1813

3. Dobbins RL, Chester MW, Daniels MB, McGarry JD, Stein DT. Circulating fatty acids are essential for efficient glucose-stimulated insulin secretion after prolonged fasting in humans. Diabetes (1998) 47:1613-8. doi:10.2337/diabetes.47. 10.1613

4. Takeda S, Kadowaki S, Haga T, Takaesu H, Mitaku S. Identification of G proteincoupled receptor genes from the human genome sequence. FEBS Lett (2002) 520:97-101. doi:10.1016/S0014-5793(02)02775-8

5. Itoh Y, Kawamata Y, Harada M, Kobayashi M, Fujii R, Fukusumi S, et al. Free fatty acids regulate insulin secretion from pancreatic beta cells through GPR40. Nature (2003) 422:173-6. doi:10.1038/nature01478

6. Briscoe CP, Tadayyon M, Andrews JL, Benson WG, Chambers JK, Eilert MM, et al. The orphan G protein-coupled receptor GPR40 is activated by medium and long chain fatty acids. J Biol Chem (2003) 278:11303-11. doi:10.1074/jbc. M211495200

7. Hirasawa A, Itsubo C, Sadakane K, Hara T, Shinagawa S, Koga H, et al. Production and characterization of a monoclonal antibody against GPR40 (FFAR1; free fatty acid receptor 1). Biochem Biophys Res Commun (2008) 365:22-8. doi:10.1016/j.bbrc.2007.10.142

8. Meidute Abaraviciene S, Muhammed SJ, Amisten S, Lundquist I, Salehi A. GPR40 protein levels are crucial to the regulation of stimulated hormone secretion in pancreatic islets. Lessons from spontaneous obesity-prone and non-obese type 2 diabetes in rats. Mol Cell Endocrinol (2013) 381:150-9. doi:10.1016/j.mce.2013.07.025

9. Tomita T, Masuzaki H, Noguchi M, Iwakura H, Fujikura J, Tanaka T, et al. GPR40 gene expression in human pancreas and insulinoma. Biochem Biophys Res Commun (2005) 338:1788-90. doi:10.1016/j.bbrc.2005.10.161

10. Tomita T, Masuzaki H, Iwakura H, Fujikura J, Noguchi M, Tanaka T, et al. Expression of the gene for a membrane-bound fatty acid receptor in the pancreas and islet cell tumours in humans: evidence for GPR40 expression in pancreatic beta cells and implications for insulin secretion. Diabetologia (2006) 49:962-8. doi:10.1007/s00125-006-0193-8

11. Odori S, Hosoda K, Tomita T, Fujikura J, Kusakabe T, Kawaguchi Y, et al. GPR119 expression in normal human tissues and islet cell tumors: evidence for its islet-gastrointestinal distribution, expression in pancreatic beta and alpha cells, and involvement in islet function. Metabolism (2013) 62:70-8. doi:10.1016/j.metabol.2012.06.010

12. Kebede M, Ferdaoussi M, Mancini A, Alquier T, Kulkarni RN, Walker $\mathrm{MD}$, et al. Glucose activates free fatty acid receptor 1 gene transcription via phosphatidylinositol-3-kinase-dependent O-GlcNAcylation of pancreasduodenum homeobox-1. Proc Natl Acad Sci U S A (2012) 109:2376-81. doi:10.1073/pnas.1114350109

13. Bartoov-Shifman R, Ridner G, Bahar K, Rubins N, Walker MD. Regulation of the gene encoding GPR40, a fatty acid receptor expressed selectively in pancreatic beta cells. J Biol Chem (2007) 282:23561-71. doi:10.1074/jbc.M702115200

14. Steneberg P, Rubins N, Bartoov-Shifman R, Walker MD, Edlund H. The FFA receptor GPR40 links hyperinsulinemia, hepatic steatosis, and impaired glucose homeostasis in mouse. Cell Metab (2005) 1:245-58. doi:10.1016/j.cmet. 2005.03.007

15. Kebede M, Alquier T, Latour MG, Semache M, Tremblay C, Poitout V. The fatty acid receptor GPR40 plays a role in insulin secretion in vivo after high-fat feeding. Diabetes (2008) 57:2432-7. doi:10.2337/db08-0553
16. Lan H, Hoos LM, Liu L, Tetzloff G, Hu W, Abbondanzo SJ, et al. Lack of FFAR1/GPR40 does not protect mice from high-fat diet-induced metabolic disease. Diabetes (2008) 57:2999-3006. doi:10.2337/db08-0596

17. Latour MG, Alquier T, Oseid E, Tremblay C, Jetton TL, Luo J, et al. GPR40 is necessary but not sufficient for fatty acid stimulation of insulin secretion in vivo. Diabetes (2007) 56:1087-94. doi:10.2337/db06-1532

18. Alquier T, Peyot ML, Latour MG, Kebede M, Sorensen CM, Gesta S, et al. Deletion of GPR40 impairs glucose-induced insulin secretion in vivo in mice without affecting intracellular fuel metabolism in islets. Diabetes (2009) 58:2607-15. doi:10.2337/db09-0362

19. Nagasumi K, Esaki R, Iwachidow K, Yasuhara Y, Ogi K, Tanaka H, et al. Overexpression of gpr40 in pancreatic $\beta$-cells augments glucose stimulated insulin secretion and improves glucose tolerance in normal and diabetic mice. Diabetes (2009) 58:1067-76. doi:10.2337/db08-1233

20. Edfalk S, Steneberg P, Edlund H. Gpr40 is expressed in enteroendocrine cells and mediates free fatty acid stimulation of incretin secretion. Diabetes (2008) 57:2280-7. doi:10.2337/db08-0307

21. Parker HE, Habib AM, Rogers GJ, Gribble FM, Reimann F. Nutrientdependent secretion of glucose-dependent insulinotropic polypeptide from primary murine K cells. Diabetologia (2009) 52:289-98. doi:10.1007/s00125008-1202-x

22. Liou AP, Lu X, Sei Y, Zhao X, Pechhold S, Carrero RJ, et al. The G-proteincoupled receptor GPR40 directly mediates long-chain fatty acid-induced secretion of cholecystokinin. Gastroenterology (2011) 140:903-12. doi:10.1053/j. gastro.2010.10.012

23. Negoro N, Sasaki S, Mikami S, Ito M, Suzuki M, Tsujihata Y, et al. Discovery of TAK-875: a potent, selective, and orally bioavailable GPR40 agonist. ACS Med Chem Lett (2010) 1:290-4. doi:10.1021/ml1000855

24. Tsujihata Y, Ito R, Suzuki M, Harada A, Negoro N, Yasuma T, et al. TAK-875, an orally available $\mathrm{G}$ protein-coupled receptor 40 /free fatty acid receptor 1 agonist, enhances glucose-dependent insulin secretion and improves both postprandial and fasting hyperglycemia in type 2 diabetic rats. J Pharmacol Exp Ther (2011) 339:228-37. doi:10.1124/jpet.111.183772

25. Yashiro H, Tsujihata Y, Takeuchi K, Hazama M, Johnson PR, Rorsman P. The effects of TAK-875, a selective G protein-coupled receptor 40/free fatty acid 1 agonist, on insulin and glucagon secretion in isolated rat and human islets. J Pharmacol Exp Ther (2012) 340:483-9. doi:10.1124/jpet.111.187708

26. Burant CF, Viswanathan P, Marcinak J, Cao C, Vakilynejad M, Xie B, et al. TAK875 versus placebo or glimepiride in type 2 diabetes mellitus: a phase 2, randomised, double-blind, placebo-controlled trial. Lancet (2012) 379:1403-11. doi:10.1016/S0140-6736(11)61879-5

27. Kaku K, Araki T, Yoshinaka R. Randomized, double-blind, dose-ranging study of TAK-875, a novel GPR40 agonist, in Japanese patients with inadequately controlled type 2 diabetes. Diabetes Care (2013) 36:245-50. doi:10.2337/ dc12-0872

Conflict of Interest Statement: The authors declare that the research was conducted in the absence of any commercial or financial relationships that could be construed as a potential conflict of interest.

Received: 12 June 2014; accepted: 12 September 2014; published online: 26 September 2014

Citation: Tomita T, Hosoda K, Fujikura J, Inagaki N and Nakao K (2014) The Gprotein-coupled long-chain fatty acid receptor GPR40 and glucose metabolism. Front. Endocrinol. 5:152. doi: 10.3389/fendo.2014.00152

This article was submitted to Diabetes, a section of the journal Frontiers in Endocrinology.

Copyright (c) 2014 Tomita, Hosoda, Fujikura, Inagaki and Nakao. This is an openaccess article distributed under the terms of the Creative Commons Attribution License (CC BY). The use, distribution or reproduction in other forums is permitted, provided the original author(s) or licensor are credited and that the original publication in this journal is cited, in accordance with accepted academic practice. No use, distribution or reproduction is permitted which does not comply with these terms. 